DOI: 10.17805/zpu.2015.3.7

\title{
Специфика социально-политического самоопределения современной российской молодежи
}

\author{
А. Л. ЕЛИСЕЕВ, Е. Н. МАЛИК, А. В. МЕЛЬНИКОВ \\ (ОРЛОВСКИЙ ФИЛИАЛ РОССИЙСКОЙ АКАДЕМИИ НАРОДНОГО ХОЗЯЙСТВА \\ И ГОСУДАРСТВЕННОЙ СЛУЖБЫ ПРИ ПРЕЗИДЕНТЕ РОССИЙСКОЙ ФЕДЕРАЦИИ)
}

В статье раскрываются проблемы формирования и реализации политического потенциала нового поколения российской молодежи. Авторы останавливаются на специфике становления политической позиции молодых граждан. Анализируется специфика политических и социальных ресурсов молодежи как особой социально-демографической группы, которая тем не менее не обладает целостностью. Внутренняя социальная, экономическая и политическая дифференциация определяет дальнейшее участие молодого поколения в общественно-политической жизни страны. Приводится дифференциация ценностных представлений молодежи, обусловливающих степень ее включения в политическую и социальную сферы российского общества.

В статье проанализированы результаты социологических исследований процесса интеграции молодежи в социально-политические практики, в том числе Фонда общественного мнения «О молодежи: возрастные границы, ценности, особенности» (2014), «Молодежь Орловской области в 2015 году» (2015). В качестве показателя социально-политического самоопределения российской молодежи рассматривается уровень ее интереса к политическим событиям. С одной стороны, молодежь имеет необходимый потенциал влияния на политическую сферу государства, а с другой - нуждается в поддержке своей социальной активности со стороны государственных и общественных институтов. Авторы показывают, что молодых граждан отличает лабильность сознания, неустойчивость политических ориентаций и взглядов. Данные характеристики молодежной группы могут способствовать ее дезорганизации и развитию протестного поведения.

Обоснованы перспективы реализации политического потенциала молодых граждан. Политическое воспитание имеет первостепенное значение в становлении политической субъектности молодежи в современных российских условиях. Авторы акцентируют внимание на объективных и субъективных факторах, влияющих на процессы политической социализации и участия молодежи в политическом процессе страны.

Ключевые слова: молодежь, российская молодежь, политический процесс, политический потенциал, политическая субъектность, политическое участие, политическая социализация.

\section{BВЕАЕНИЕ}

$\mathrm{M}$ олодое поколение выполняет особые социальные функции: наследует достигнутый уровень развития общества и государства; является главным объектом воспитания и образования, адаптации и социализации; выступает ведущим субъектом социальных перемещений и экономической мобильности; несет функцию социального воспроизводства. Молодые граждане выступают основным стратегическим ресурсом нации, являются главными проводниками научно-технического и социально-экономического прогресса, а также передовых идей и инноваций глобального мира. Их творческое воображение, оперативность и энергия имеют большое значение для обеспечения постоянного движения общества вперед.

Цель настоящей статьи - выявить специфику политических и социальных ресурсов молодежи как особой социально-демографической группы, которая тем не менее не обладает целостностью. 


\section{СОЦИААЬНО-ПОАИТИЧЕСКОЕ САМООПРЕАЕАЕНИЕ РОССИЙСКОЙ МОАОАЕЖИ}

Современная молодежь призвана обеспечивать социальную мобильность общества, выступать источником социально-политических и экономических инициатив, что обеспечивает полноценное развитие всех сфер жизни социума. Сегодня российская молодежь находится в стадии своего становления и освоения новых социальных и политических ролей. Мы не можем не согласиться с мнением российских ученых, что «проблема трансформации культурных ценностей под влиянием инноваций все более актуальна в современных российских условиях, когда позиции "консерваторов" начинают ослабевать, расчищая дорогу новым идеям и инновациям, берущим начало из молодежной среды» (Государственная молодежная политика ..., 2013: 203).

Если рассмотреть молодежь в целом как особую социальную группу, следует выявить ее общие функции и характеристики. О них, в частности, пишут И. М. Ильинский и Вал. А. Ауков:

- молодежь, наследуя социокультурный и политический опыт предшествующих поколений и обеспечивая преемственность достигнутого уровня общественного развития, выступает основным стратегическим ресурсом воспроизводства социума;

- молодежь обладает существенным инновационным потенциалом, реализация которого в зависимости от социально-экономических условий и влияния политических сил может иметь как конструктивную, так и деструктивную направленность. Неопределенность идейно-политических взглядов молодого поколения создает благоприятные условия для манипулирования со стороны различных политических сил и способствует осуществлению их властных интересов;

- молодое поколение играет значимую роль в обеспечении необходимого уровня обороноспособности, безопасности и защиты государства;

- новый квалификационный уровень молодых людей, который существенно отличается от предшествующих поколений, способность быстро адаптироваться к изменяющимся условиям высоко востребованы в современной рыночной экономике (Ильинский, Ауков, 2008).

Вместе с тем молодежь как социально-демографическая группа не представляет определенной целостности, а характеризуется внутренней социальной и политической дифференциацией.

Представленный рисунок указывает на характерные особенности молодежи, которая как социально-демографическая группа не представляет определенной целостности, отличается внутренней социальной, экономической и политической дифференциацией. «Принадлежность к той или иной молодежной страте во многом детерминирует функциональную роль молодых людей в жизнедеятельности общества, что определяет их дальнейшее участие в общественно-политической жизни страны» (Малик, Мельников, 2015: 72).

За последние годы заметно изменилось понимание «демократии» в молодежной среде. Если в 2012 г. 47\% молодых граждан полагали, что «демократия - это прежде всего свобода слова, печати и собраний», то в 2015 г. так думают лишь $39 \%$ респондентов. В то же время число тех, кто считает признаком демократии свободные выборы всех органов власти, уменьшилось за три года с 28 до 19\%, а количество тех, кто видит в демократии возможность граждан контролировать власти, - с 39 до 18\%. Заместитель директора «Иевада-центра» А. Гражданкин отмечает: «...понятие демократии 
Молодежь как социально-демографическая группа
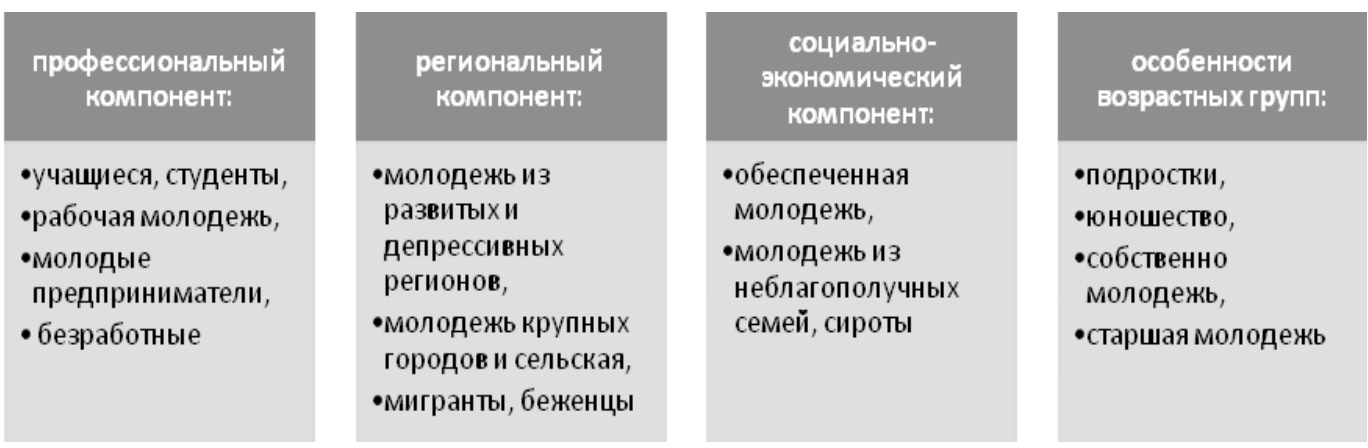

Основные компоненты дифференииачии молодежной группь

The main differentials of a youth group

зависит от ее трактовки руководством страны и СМИ, в России свобода слова существует ограниченно, хотя для населения эта категория - по-прежнему ключевой признак демократии. В 2012 г. на волне протестов это восприятие усиливалось, а сейчас сократилось вместе с реалиями, демократию же россияне связывают с материальными благами» (цит. по: Чуракова, 2015: Электронный ресурс).

Так, например, по данным исследования 2014 г. Фонда «Общественное мнение» «О молодежи: возрастные границы, ценности, особенности» (опрос 1500 граждан РФ от 18 лет и старше в 43 субъектах РФ, 100 населенных пунктах; интервью по месту жительства), у молодых людей из больших и средних городов заметнее выражены демократические настроения (разница свыше $10 \%$ по отношению с селянами) (О молодежи ..., 2014: Электронный ресурс). Им свойственна более высокая оценка собственных возможностей влиять на ситуацию в стране, проявляя общественную и гражданскую активность.

Учитывая вышесказанное, обратимся к результатам социологического исследования, проведенного с целью составления социально-политического портрета молодежи Орловской области. В качестве респондентов выступила молодежь Орловской области в возрасте 15-29 лет. Метод сбора информации - индивидуальное анкетирование. Сроки опроса - февраль - март 2015 г. В опросе использовалась квотная выборка по трем признакам: полу, возрасту и численности молодежи в населенных пунктах. Место опроса: г. Орел и другие населенные пункты Орловской области (Орловского, Аивенского, Мценского и Кромского районов). Всего было опрошено 404 респондента. Полученная выборочная совокупность состоит из 48,8\% мужчин и 51,2\% женщин (Исследование «Молодежь Орловской области в 2015 году», 2015). Следует отметить, что особенностью социально-политического самоопределения молодежи является в той или иной степени ее интерес к политическим событиям: около $40 \%$ опрошенной молодежи это декларируют; не интересуются политикой - 59\%. То, что политика, политическая жизнь является фоновой сферой для значительной части молодежи, вполне закономерно, учитывая, что в этом возрасте главное внимание сконцентрировано на учебе и семье, а также работе. Как видно из данных таблицы, политика, общественная деятельность являются приоритетными лишь для 4\% опрошенных молодых граждан. 
СФЕРЫ ЖИЗНИ АЮАЕЙ, В НАИБОАЬШЕЙ СТЕПЕНИ ВАЖНЫЕ ААЯ МО ОАЕЖИ, В \% ОТ ОБЩЕГО ЧИС АА ОПРОШЕННЫХ

SPHERES OF LIFE MOST IMPORTANT FOR THE YOUTH, $\%$ OF TOTAL RESPONDENTS

\begin{tabular}{|l|c|}
\hline \multicolumn{1}{|c|}{ Сфера деятельности } & Omветь \\
\hline Учеба, образование & 69 \\
Семья, дети, дом & 67 \\
Работа, карьера, продвижение по службе & 48 \\
Аосуг, развлечения, туризм & 16 \\
Физическая культура, спорт & 13 \\
Религия, вера & 5 \\
Политика, общественная деятельность & 4 \\
\hline
\end{tabular}

Примечание: респонденты могли выбирать по нескольку вариантов ответа.

По мере увеличения социальных связей (в институте, армии, на работе и т. А.) происходит перераспределение жизненных интересов молодых граждан в сторону общественного и политического участия. Так, в младшей возрастной группе молодежи 17-20 лет в целом интерес к политике в той или иной степени демонстрируют 41\%, в средней (21-23 лет) - 48\%, в старшей (24-30 лет) - 57\%. Причем в старшей группе доля интересующихся политикой превосходит число тех, кто ею не интересуется $(57 \%$ против 42\%). Также заметно больший интерес к политике проявляет молодежь, которая довольна своим материальным положением (по сравнению с теми, кто оценивает это положение со знаком «минус») (Меркулов, Малик, Бударина, 2015).

Следует сказать, что положение молодежи в условиях системной трансформации российского общества сохраняет противоречивый характер. Во-первых, молодежь является социальной базой общественных изменений и более адаптивна к новым социально-политическим реалиям. Молодым людям свойственно проявлять стремление и демонстрировать свою индивидуальность, а благодаря групповым факторам активности и своему потенциалу они имеют возможность влиять на политическую сферу государства.

Во-вторых, молодое поколение как объект государственной молодежной политики только начинает входить в систему общественных отношений, вследствие чего является наиболее уязвимой общностью и нуждается в поддержке государственных и общественных институтов (Ауков, 2013).

Нельзя забывать, что данную тенденцию могут использовать организации псевдопатриотической и антисоциальной направленности, что приводит к дезорганизации молодежи, разрушению массовой культуры, подмене ценностей и культурных кодов, разжиганию русофобии в молодежной среде, а также уничтожению исторической памяти (Евгеньева, Титов, 2010). Примером этого могут служить такие протестные акции, как «Марш миллионов» по Большой Якиманке до Болотной площади, состоявшийся 6 мая 2012 г., воскресный марш памяти Б. Немцова 1 марта 2015 г. и т. п. 
По нашему мнению, одним из факторов вовлечения молодых граждан, а именно студенчества, в ряды протестного движения является их осознание низкой степени реального участия в политической жизни страны. «Амбивалентность и несформированность политических взглядов молодежи создают предпосылки для манипулирования ее сознанием со стороны различных этнонационалистических группировок на фоне доминирования этнической идентичности над гражданственностью» (Новиченко, 2013: 52). Напротив, оппозиция обещает молодежи такую возможность на примерах простых людей, ставших известными благодаря активному участию в революционных движениях, от Че Гевары до Навального.

Молодое поколение, как правило, не способно самостоятельно разобраться и проанализировать изменения политического процесса. На разных этапах развития общество предъявляет молодежи определенные требования в виде норм, моральных установок и ценностей, а как известно, политические ориентации и установки молодого поколения нестабильны и легко поддаются манипулированию со стороны различных политических сил. Учитывая социально-психологическую специфику молодежи, лабильность сознания, неустойчивость политических ориентаций, молодых людей необходимо политически воспитывать, чтобы они осознали значимость собственного положения в обществе и свою политическую силу. «Задача государства и институтов гражданского общества - воспитать современную молодежь как активного субъекта формирования государственной молодежной политики. Именно сегодня представляется важным выстроить эффективные механизмы включения молодежи в созидательные процессы развития России» (Меркулов, Малик, 2015: 140).

Обратимся к данным, полученным Всероссийским центром изучения общественного мнения (ВЦИОМ) в ходе опроса о том, хотят ли наши сограждане повторения событий, подобных украинскому «Евромайдану», в России и насколько вероятным считают подобные массовые политические акции протеста. На вопрос, хотели бы ди респонденты повторения украинского Майдана-2014 в России, они отвечают практически единогласно: 94\% не желают реализации схожего сценария у нас в стране (в феврале 2014 г. этот ответ также дали 94\%). С этим в равной степени согласны молодые (94\% от 18 до 24 лет) и пожилые (93\% старше 60 лет) люди. Три четверти опрошенных $(76 \%)$ уверены, что в российском государстве акции протеста, подобные «Евромайдану», в принципе невозможны (за год эта доля практически не изменилась: 75\% в феврале 2014 г.). Аанную точку зрения в большей степени разделяют респонденты с высокими доходами (80\%), обучавшиеся в вузах $(79 \%)$, нежели малообеспеченные $(71 \%)$ и малообразованные (65\%) (Пресс-выпуск ..., 2015: Электронный ресурс).

На этом фоне задача «всех акторов политической социализации молодежи - оградить наше подрастающее поколение от участия в протестных акциях, не допустить политической мобилизации студенчества на исполнение воли зарубежных политтехнологов» (Елишев, 2015: 208).

Политическое образование и политическая культура молодежи во многом определяют ее возможность и способность к реализации своих гражданских прав, а также определяют направленность ее политической деятельности. Стоит подчеркнуть, что политическое воспитание современной российской молодежи протекало в период социально-экономического кризиса и политической нестабильности (Меркулов, Елисеев, 2014). Мы приходим к пониманию, что содержание и особенности политической социализации молодого поколения зависят от таких факторов, как: 
- последствия политических реформ нового времени и социального расслоения населения по степени владения собственностью и уровню доходов;

- занятость молодежи, ее положение на рынке труда как сфера молодежной политики местной власти и местного сообщества;

- общественно-политическая активность молодежи, ее участие в политическом процессе;

- ослабление влияния на молодежь традиционных агентов политической социализации (семьи, системы образования и воспитания, коллективов сверстников и т. А.);

- дефицит управляемости процессом политической социализации молодежи со стороны местного сообщества и органов власти.

Таким образом, политические и общественные институты должны создавать условия для включения молодежи в систему политической жизни общества. Содержание и направленность этого процесса во многом определят дальнейшее участие молодого поколения в преобразованиях и совершенствовании общественной системы. О. В. Сорокин справедливо отмечает: «Воспитание на принципах толерантности, политкорректности, гражданственности, патриотизма, ответственности, доверия к действиям государственной власти способствует успешной интеграции молодежи в политическое и социальное пространство, идентификации с общими ценностями и нормами. В свою очередь, это является залогом воспроизводства общества и его стабильности» (Сорокин, 2007: 52).

Сегодня встает необходимость противодействия угрозе «майданов» в России через создание общероссийской сети организаций нового формата (молодежных, общественно-политических, военно-исторических, спортивных и т. д.), «заряженных» ярко выраженной патриотической, «антимайданной» идеологией (Манойло, 2015: Электронный ресурс). Подобного рода объединения должны быть нацелены на проведение широкой информационно-разъяснительной работы с молодежью относительно специфики технологий переворотов и «цветных революций», их целей, задач, истории вопроса и сценария для России. «Учитывая специфику и креативность молодежной группы, основными медийными площадками являются блоги, группы в социальных сетях, «паблики», форумы и т. А. (Малик, 2007: 119).

Здесь доминирующие позиции принадлежат органам молодежного представительства: молодежные парламенты, молодежные общественные палаты, молодежные правительства и иные консультативно-совещательные структуры, созданные при органах законодательной и исполнительной власти разного уровня, а также структурах местного самоуправления. Аанные институциональные структуры являются оптимальной в современных условиях России формой сочетания государственных, общественных и, в первую очередь, собственно молодежных интересов.

Мы разделяем мнение И. В. Кирдяшкина, что российская власть не представляет собой неделимого в культурном и идеологическом отношении политического феномена, каждый его сегмент способен сконструировать свой проект, направленный на консолидацию всех политических и социальных институтов. Учитывая свойства политической субъектности молодежи, «участие молодежных объединений в качестве каналов трансляции идеологических установок и ценностных предпочтений сближает позиции разных сторон, формируя пространство для установления коммуникаций между ними» (Кирдяшкин, 2009: 274).

Значимую роль в данном направлении призваны сыграть институты образования. Современный вуз выступает неоспоримым лидером по привлечению молодых людей 
к крупным проектам, которые дают возможность наиболее активной части студенчества реализоваться и сделать шаг к профессиональному росту (Меркулов, 2013).

\section{ВЫВОАЫ}

Особенности состояния и этапы развития общества существенным образом определяют особенности стиля жизни и специфический набор ценностей молодого поколения. При этом за последние годы усилилась ориентированность российской молодежи на ценности индивидуализма, достижений, самостоятельности и конкурентоспособности. Наряду с ними молодые люди разделяет основные демократические ориентиры, а именно права и свободу граждан, однако при этом не проявляют должного уровня интереса к политической жизни общества. За желанием части молодых граждан оставаться в стороне от политической сферы многие исследователи видят доминирование индивидуалистических образцов поведения и полагают, что при изучении политического сознания молодежной когорты нужно обращаться сначала к анализу ценностных ориентаций, а потом политических установок.

Сегодня политические акторы, а также общественные и коммерческие группы и объединения стремятся оказать влияние на мировоззрение молодежи, формирование и реализацию ее политического потенциала, привлечь на свою сторону молодое поколение, чем упрочить свои позиции.

В данной связи политическая социализация современной российской молодежи должна осуществляться с целью полноценной интеграции молодого поколения в общественные и политические структуры, которые бы смогли нейтрализовать протестные настроения среди наиболее активных социальных слоев населения, прежде всего студенчества. Аальнейшее построение эффективной модели политической социализации молодежи, по нашему мнению, целесообразно проводить с опорой на конструктивное сотрудничество государства, СМИ и институтов гражданского общества (Меркулов, Елисеев, 2014). Ведь одной из особенностей молодежи является ее открытость и способность к гражданскому диалогу, который, на наш взгляд, является наиболее качественным и быстрым средством достижением компромисса на пути построения демократического государства.

\section{СПИСОК АИТЕРАТУРЫ}

Государственная молодежная политика: российская и мировая практика реализации в обществе инновационного потенциала новых поколений (2013) : науч. монография / под общ. ред. В. А. Аукова. М. : Изд-во Моск. гуманит. унт-та. 718 с.

Евгеньева, Т. В., Титов, В. В. (2010) Формирование национально-государственной идентичности российской молодежи // Политические исследования. № 4. С. 122-134.

Елишев, С. О. (2015) Молодежь как объект социализации и манипуляции. М. : «Канон+» РООИ «Реабилитация». 320 с.

Ильинский, И. М., Ауков, В. А. (2008) Государственная молодежная политика в России: философия преемственности и смены поколений // Знание. Понимание. Умение. № 4. С. 5-14.

Исследование «Молодежь Орловской области в 2015 году» (2015) // Информационно-социологический бюллетень / под общ. ред. П. А. Меркулова. Орел : ИзА-во ОФ РАНХиГС. 72 с. C. $40-41$.

Кирдяшкин, И. В. (2009) Ценностный аспект политической социализации молодежи // Известия Алтайского государственного университета. № 4-1. С. 272-274.

Ауков, В. А. (2013) О сущности молодежной политики и ее базовых положениях [Электронный ресурс] // Информационный гуманитарный портал «Знание. Понимание. Умение». № 5 
(сентябрь - октябрь). URL: http://zpu-journal.ru/e-zpu/2013/5/Lukov_Matter-Youth-Policy/ [архивировано в WebCite] (дата обращения: 12.06.2015).

Малик, Е. Н. (2007) Влияние средств массовой информации на политическую активность молодежи в современной России: особенности, перспективы оптимизации : дис. ... канд. полит. наук. Орел. 216 с.

Малик, Е. Н., Мельников, А. В. (2015) Становление политической субъектности российской молодежи в условиях современности // Среднерусский вестник общественных наук. № 2 (38). C. $70-75$.

Манойло, А. В. (2015) Противодействие распространению идеологии цветных революций в молодежной среде [Электронный ресурс]// Мировая политика. № 1. С. 180-191. URL: http:// e-notabene.ru/wi/article_12667.html [архивировано в WebCite] (дата обращения: 12.03.2015).

Меркулов, П. А. (2013) Реализация государственной молодежной политики в Орловской области // Знание. Понимание. Умение. № 4. С. 60-64.

Меркулов, П. А., Елисеев, А. А. (2014) Формирование молодежной политики в Российской Федерации // Среднерусский вестник общественных наук. № 3 (33). С. 301-305.

Меркулов, П. А., Малик, Е. Н. (2015) Разработка государственной молодежной политики в России: история и современность // Вестник Орловского государственного университета. Серия: Новые гуманитарные исследования. № 2 (43). С. 137-141.

Меркулов, П. А., Малик, Е. Н., Бударина, К. А. (2015) Институционализация молодежных организаций и ассоциаций в современной России: проблемы и перспективы // Власть. № 4. C. $140-145$.

Новиченко, О. В. (2013) Основные тенденции трансформации политических ценностей молодежи современной России // Теория и практика общественного развития. № 9. С. 50-53.

О молодежи: возрастные границы, ценности, особенности (2014) [Электронный ресурс] // ФOM. 3 октября. URL: http://fom.ru/TSennosti/11748 [архивировано WebCite] (дата обращения: 05.02.2015).

Пресс-выпуск № 2791. «Майдан в России: маловероятно и нежелательно». (2015) [Электронный ресурс]// ВЦИОМ. 11 марта. URL: http://wciom.ru/index.php?id=236\&uid=115177 [архивировано в WebCite] (дата обращения: 12.03.2015).

Сорокин, О. В. (2007) Особенности формирования политического сознания современной российской молодежи // Власть. № 8. С. 48-52.

Чуракова, О. (2015) Большинство россиян предпочитают демократии порядок - « Аевадацентр» [Электронный ресурс] // Ведомости. 14 апреля. URL: http://vedomosti.ru/politics/articles/2015/04/15/ bolshinstvo-rossiyan-predpochitayut-demokratii-poryadok-levada-tsentr [архивировано WebCite] (дата обращения: 12.06.2015).

Aата поступления: 13.06 .2015 2.

\section{SPECIFIC FEATURES OF SOCIAL AND POLITICAL SELF-DETERMINATION IN CONTEMPORARY RUSSIAN YOUTH \\ A. L. ElISEEV, E. N. MALIK, A. V. MELNIKOV \\ (RUSSiAn PRESIDENTIAL ACADEMY Of NATIONAL ECONOMY and Public Administration, Oryol branch)}

The article looks at the issues of the developing and actualizing the political capability of the new generation of the Russian youth, with a special focus on the specific details of the youth's political positions. We analyze the political and social resources of the younger generation as a special cohort of society, which at the same time does not appear as a unified group. Further participation of young people in the social and political life of their country will be determined by the youth's internal social, economic and political differentiation. In the article, we outline the structure of value ideas among the youth, which is a crucial factor for its level of involvement in the political and social life of Russian society. 
We have analyzed the outcomes of sociological studies of how youth is integrated in social and political practices, including "Youth: Age Limits, Values, Specific Features" by the Public Opinion Foundation (FOM) (2014), and "The Youth of the Oryol Oblast in 2015" (2015). We have chosen the level of interest in political events as an indicator of socio-political self-determination of the Russian youth. On the one hand, young people do possess the required capability of influencing the political sphere, but on the other, their social activity requires support from both the state and public institutes. As the research has shown, lability of consciousness and instability of political orientations and views are typical for young citizens. These characteristics can promote disorganization and development of protest behavior among the youth.

Also outlined are the prospects of actualizing the political capabilities of Russia's young citizens. Political education is paramount for the rise of formation of political subjectness of the youth in contemporary Russia. We have focused on the objective and subjective factors influencing both political socialization of the youth and its participation in the political process of the country.

Keywords: youth, Russian youth, political process, political capability, political subjectness, political participation, political socialization.

\section{REFERENCES}

Gosudarstvennaia molodezhnaia politika: rossiiskaia i mirovaia praktika realizatsii $v$ obshchestve innovatsionnogo potentsiala novykb pokolenii [State youth policy: Russian and world practice of realization of innovative potential of new generations in society] (2013) : monograph / ed. by V. A. Lukov. Moscow, Moscow University for the Humanities Publ. 718 p. (In Russ.).

Evgenieva, T. V. and Titov, V. V. (2010) Formirovanie natsional'no-gosudarstvennoi identichnosti rossiiskoi molodezhi [Shaping the national and state identity of Russian youth]. Politicheskie issledovaniia, no. 4, pp. 122-134. (In Russ.).

Elishev, S. O. (2015) Molodezb' kak ob»ekt sotsializatsii i manipuliatsii [Youth as an object of socialization and manipulation]. Moscow, "Kanon+" Publ., RPOD "Reabilitatsiia". 320 p. (In Russ.).

Ilinskiy, I. M. and Lukov, V. A. (2008) Gosudarstvennaia molodezhnaia politika v Rossii: filosofia preemstvennosti i smeny pokolenii [State youth policy in Russia: The philosophy of continuity and generation change]. Znanie. Ponimanie. Umenie, no. 4, pp. 5-14. (In Russ.).

Issledovanie «Molodezh' Orlovskoi oblasti v 2015 godu» [The youth of Oryol oblast in the year 2015: A Study]. (2015) In: Informatsionno-sotsiologicheskii biulleten' / ed. by P. A. Merkulov. Oryol, RANEPA Publ. (Oryol branch).72 p. Pp. 37-71. (In Russ.).

Kirdiashkin, I. V. (2009) Tsennostnyi aspekt politicheskoi sotsializatsii molodezhi [Value aspect of political socialization of the youth]. Izvestiia altaiskogo gosudarstvennogo universiteta, no. 4-1, pp. 272-274. (In Russ.).

Lukov, V. A. (2013) O sushchnosti molodezhnoi politiki i ee bazovykh polozheniiakh [On the subject matter of youth policy and its basic regulations]. Informatsionnyi gumanitarnyi portal "Znanie. Ponimanie. Umenie", no. 5 (September - October). [online] Available at: http://zpu-journal.ru/e-zpu/2013/5/Lukov_Matter-Youth-Policy/ [archived in WebCite] (accessed 12.06.2015). (In Russ.).

Malik, E. N. (2007) Vliianie sredstv massovoi informatsii na politicheskuiu aktivnost' molodezbi $v$ sovremennoi Rossii: osobennosti, perspektivy optimizatsii [The influence of mass media on the political activism of the youth in contemporary Russia: Specific features and optimization prospects] : diss. ... Candidate of Political Science. Oryol. 216 p. (In Russ.).

Malik, E. N. and Melnikov, A. V. (2015) Stanovlenie politicheskoi sub'ektnosti rossiiskoi molodezhi $\mathrm{v}$ usloviiakh sovremennosti [The rise of political subjectness of contemporary Russian youth]. Srednerusskii vestnik obshchestvennykb nauk, no. 2 (38), pp. 70-75. (In Russ.).

Manoilo, A. V. (2015) Protivodeistvie rasprostraneniiu ideologii tsvetnykh revoliutsii v molodezhnoi srede [Preventing the spread of the ideology of color revolutions among youth]. Mirovaia politika, no. 1, pp. 180-191. [online] Available at: http://e-notabene.ru/wi/article_12667.html [архивировано в WebCite] (accessed 12.03.2015). (In Russ.). 
Merkulov, P. A. and Eliseev, A. L. (2014) Formirovanie molodezhnoi politiki v Rossiiskoi Federatsii [The formation of youth policy in Russian Federation]. Srednerusskii vestnik obshchestvennykb nauk, no. 3 (33), pp. 301-305. (In Russ.).

Merkulov, P. A. and Malik, E. N. (2015) Razrabotka gosudarstvennoi molodezhnoi politiki v Rossii: istoriia i sovremennost' [Working out the state youth policy in Russia: history and modernity]. Vestnik Orlovskogo gosudarstvennogo universiteta. Seriia: Novye gumanitarnye issledovaniia, no. 2 (43), pp. 137-141. (In Russ.).

Merkulov, P. A. (2013) Realizatsiia gosudarstvennoi molodezhnoi politiki v Orlovskoi oblasti [Implementation of the state youth policy in Oryol Oblast]. Znanie. Ponimanie. Umenie, no. 4, pp. 60-64. (In Russ.).

Merkulov, P. A., Malik, E. N. and Budarina, K. A. (2015) Institutsionalizatsiia molodezhnykh organizatsii $\mathrm{i}$ assotsiatsii $\mathrm{v}$ sovremennoi Rossii: problemy i perspektivy [Institutionalization of youth organizations and associations in contemporary Russia: problems and prospects]. Vlast', no. 4, pp. 140-145. (In Russ.).

Novichenko, O. V. (2013) Osnovnye tendentsii transformatsii politicheskikh tsennostei molodezhi sovremennoi Rossii [Major trends in the transformation of political values of youth in contemporary Russia]. Teoriia i praktika obshchestvennogo razvitiia, no. 9, pp. 50-53. (In Russ.).

O molodezhi: vozrastnye granitsy, tsennosti, osobennosti [Youth: Age limits, values, specific features]. (2014) FOM. October 3. [online] Available at: http://fom.ru/TSennosti/11748 [archived in WebCite] (accessed 5.02.2015). (In Russ.).

Press-vypusk № 2791. «Maidan v Rossii: maloveroiatno i nezhelatel'no» [Press-release no. 2791. "The Maidan in Russia: Undesirable and unlikely"]. (2015) VTsIOM [Russian Public Opinion Research Center]. March 11. [online] Available at: http://wciom.ru/index.php?id=236\&uid=115177 [archived in WebCite] (accessed 12.03.2015). (In Russ.).

Sorokin, O. V. (2007) Osobennosti formirovaniia politicheskogo soznaniia sovremennoi rossiiskoi molodezhi [Specific features of building political consciousness of contemporary Russian youth]. Vlast', no. 8, pp. 48-52. (In Russ.).

Churakova, O. (2015) Bol'shinstvo rossiian predpochitaiut demokratii poriadok - «Levada-tsentr» [The majority of Russians prefer order to democracy - Levada Center]. Vedomosti. April 14. [online] Available at: http://vedomosti.ru/politics/articles/2015/04/15/bolshinstvo-rossiyan-predpochitayut-demokratii-poryadok-levada-tsentr [archived in WebCite] (accessed 12.06.2015). (In Russ.).

Submission date: 13.06 .2015$.

Елисеев Анатолий Аеонидович — кандидат исторических наук, доцент, заведующий кафедрой философии и социальных технологий Орловского филиала Российской академии народного хозяйства и государственной службы при Президенте РФ. Адрес: 302028, Россия, г. Орел, б-р Победы, д. 5а. Тел.: +7 (4862) 43-20-28. Эл. адрес: eliseev.anatoly@gmail.com

Малик Елена Николаевна - кандидат политических наук, доцент, доцент кафедры политологии и государственной политики Орловского филиала Российской академии народного хозяйства и государственной службы при Президенте РФ. Адрес: 302028, Россия, г. Орел, б-р Победы, д. 5а. Тел.: +7 (4862) 71-79-19. Эл. адрес: malik57-elena@mail.ru

Мельников Алексей Викторович - кандидат политических наук, доцент кафедры политологии и государственной политики Орловского филиала Российской академии народного хозяйства и государственной службы при Президенте РФ. Адрес: 302028, Россия, г. Орел, б-р Победы, д. 5а. Тел.: +7 (4862) 43-20-28. Эл. алрес: melnikov@orel.ranepa.ru

Eliseev Anatoly Leonidovich, Candidate of History, Associate Professor and Chair, Department of Philosophy and Social Technologies, Russian Presidential Academy of National Economy and Public Administration (Oryol branch). Postal address: 5a, Pobedy Blvd., 302028 Oryol, Russian Federation. Tel.: +7 (4862) 43-20-28. E-mail: eliseev.anatoly@gmail.com 
Malik Elena Nikolaevna, Candidate of Political Science, Associate Professor, Department of Political Science and Public Policy, Russian Presidential Academy of National Economy and Public Administration (Oryol branch). Postal address: 5a, Pobedy Blvd., 302028 Oryol, Russian Federation. Tel.: +7 (4862) 71-79-19. E-mail: malik57-elena@mail.ru

Melnikov Alexey Viktorovich, Candidate of Political Science, Associate Professor, Department of Political Science and Public Policy, Russian Presidential Academy of National Economy and Public Administration (Oryol branch). Postal address: 5a, Pobedy Blvd., 302028 Oryol, Russian Federation. Tel.: +7 (4862) 43-20-28. E-mail: melnikov@orel.ranepa.ru 